\title{
APLIKASI PENDATAAN LAPORAN POLISI PADA POLSEK KEDAWUNG BERBASIS WEB (STUDI KASUS : POLSEK KEDAWUNG)
}

\author{
Wiwiek Nurkomala Dewi ${ }^{1}$, Afif Sulhan ${ }^{2}$, Dita Firgi Santhia ${ }^{3}$ \\ Sekolah Tinggi Manajemen Informatika dan Komputer CIC Cirebon \\ Jl.Kesambi 202, Kota Cirebon, Jawa Barat. Telp (0231)220350 \\ Email : wiwiek.nurkomala.dewi@cic.ac.id ${ }^{1}$, sulhan.afif@gmail.com ${ }^{2}$, ditafirgi08@gmail.com $^{3}$
}

\begin{abstract}
Abstrak
Perkembangan teknologi informasi di era globalisasi ini telah mengalami perkembangan cukup pesat. Polsek Kedawung merupakan suatu instasi kepolisian yang bergerak dibidang pelayanan umum. Pada pelayanan penerimaan laporan dan pengaduan dari masyarakat, kepolisian berkewajiban menerima laporan dan pengaduan dari masyarakat yang mengalami tindak kriminal dan juga kehilangan barang berharga. Pada saat ini Polsek Kedawung belum memiliki aplikasi pendataan laporan sehingga dalam proses penyimpanan data hanya pada buku besar. Proses pendataan laporan dibuat menggunakan Microsoft word dengan cara mengganti data lama dan diganti data baru. Dalam menganalisa sistem, dilakukan penggambaran prosedur sistem yang berjalan sehingga dari sistem tersebut dapat dievaluasi kekurangan dan kelebihannya. Dalam proses pembuatan sistem tersebut dimulai dengan tahapan analisa sistem. Kemudian pemodelan proses digambarkan menggunakan flowmap, diagram konteks, diagram alir data (Data Flow Diagram), entity relationship diagram (ERD), tabel-tabel yang digunakan Rancangan Database, Rancangan Tampilan Input maupun Output yang diimplementasikan menggunakan bahasa pemograman PHP dan perangkat lunak MySql sebagai media penyimpanan data. Pendataan ini menyediakan informasi mengenai laporan model $A$, model $B$, model $C$ dan laporan surat perintah tugas, surat perintah penyidikan, surat perintah dimulainya penyidikan, surat perintah penangkapan, surat peintah penahanan, grafik laporan dan grafik surat. Dengan adanya aplikasi pendataan laporan polisi ini diharapkan dapat memudahkan dalam proses pembuatan laporan dan penyimpanan data laporan. Hasil dari aplikasi ini adalah surat laporan model A, surat laporan model B, surat laporan model C, surat perintah tugas, surat perintah penyidikan, surat perintah dimulainya penyidikan, surat perintah penangkapan, surat perintah penahanan, grafik informasi laporan dan grafik informasi surat
\end{abstract}

Katakunci: Aplikasi, Laporan Polisi, Pendataan, Surat Perintah.

\begin{abstract}
Kedawung Police Station is a police institution engaged in public services. In the service of receiving reports and complaints from the public, the police are obliged to receive reports and complaints from people who have experienced criminal acts and also lost valuable items. At this time the Kedawung Police Station does not yet have a data collection application so that in the process of storing data only on ledgers. The data collection process is made using Microsoft Word by replacing old data and replacing new data.In analyzing the system, a description of the running system procedures is carried out so that the system can be evaluated for its strengths and weaknesses. In the process of making the system begins with the system analysis stage. Then the process modeling is illustrated using flowmaps, context diagrams, data flow diagrams (Data Flow Diagrams), entity relationship diagrams (ERD), tables used in Database Design, Input and Output Display Designs which are implemented using the PHP programming language and MySql software as data storage media. This data collection provides information on reports on model $A$, model B, model $C$ and reports on task orders, investigation orders, commencement of investigations, arrest warrants, arrest warrants, report charts and graphic letters. With this police report data collection application is expected to facilitate the process of making reports and storing report data. The results of this application are model A report letter, model B report letter, model C report letter, assignment order, investigation order, warrant for commencement of investigation, arrest warrant, detention warrant, report information chart and letter information chart
\end{abstract}

Keywords:Application, Police Report, Data Collection, Warrant. 


\section{PENDAhuluan}

Pelayanan kepolisian tidak hanya pada pelayanan lalu lintas, tetapi juga pada pelayanan penerimaan laporan dan pengaduan dari masyarakat, kepolisian berkewajiban memberikan perlindungan serta menerima laporan dan pengaduan dari masyarakat yang mengalami tindak kriminal dan juga laporan kehilangan barang berharga. Penerimaan dan pengaduan ditangani oleh bagian Sentra Pelayanan Kepolisian (SPK) dan bagian Reserse Kriminal (RESKRIM)yang menindaklanjuti laporan kriminal. Sentra Pelayanan Kepolisian (SPK) harus mampu dengan cepat dan tepat dalam melayani masyarakat. Pendataan laporan secara rinci dan sesuai standar, pengelolaan data yang rapi dan lengkap, serta pembuatan surat yang tidak membutuhkan waktu yang lama.

Kantor Polsek Kedawung terletak pada Jalan Ir.Juanda No.23 Kedawung Kota Cirebon. Polsek Kedawung belum terdapat sistem pendataan laporan polisi pada bagian Sentra Pelayanan Kepolisian (SPK) dan data surat berkas perkara pada Reserse Kriminal (RESKRIM) belum menggunakan sistem yang terkomputerisasi. Laporan kriminal dan tindak pidana dibuat menggunakan Microsoft Word dengan menghapus data lama dan diganti dengan data baru. Dalam penyimpanan laporan hanya dicatat di buku besar. Akibatnya apabila bagian Sentra Pelayanan Kepolisian (SPK) dan Reserse Kriminal (RESKRIM)ingin melakukan pencarian data atau tindak lanjut perkara sulit untuk mendapatkan data-data sebelumnya. Dikarenakan adanya kemungkinan kertas laporan hilang dan data lama sudah tergantikan dengan data baru.Belum adanya grafik informasi laporan polisi pada bagian sentra pelayanan kepolisian (SPK) dan grafik informasi surat berkas perkara pada bagian reserse kriminal (RESKRIM).

Dengan adanya Aplikasi ini diharapkan kebutuhan-kebutuhan instansi terkini dan masalahmasalah yang sering terjadi pada proses pengolahan data bisa teratasi dengan baik sehingga dapat meningkatkan kinerja dari pihak terlibat dalam proses pengolahan data dan dapat menghasilkan data secara digital dalam pengarsipannya.

Oleh karena itu bedasarkan uraian diatas, penulis merasa tertarik untuk mengambil judul “Aplikasi Pendataan Laporan polisi Pada Polsek Kedawung Berbasis Web" dengan tujuan agar dapat memecahkan masalah yang timbul di instansi tersebut.

\section{KAJIAN PUSTAKA}

\subsection{Analisis}

Untuk membangun sebuah website yang baik diperlukan analisis dan perancangan dari sistem. Analisis dan perancangan ini dilakukan agar dalam pembuatan website diperoleh hasilyang dapat mempermudah pendataan di Polsek Kedawung. Dalam paper ini kami akan membuat sebuah Aplikasi Pendataan Laporan Kepolisian berbasis web dimana didalamnya berisi data laporan polisi pada Polsek Kedawung.

Oleh karena itu agar analisis tersebut dapat diimplementasikan dengan baik, maka pada bab ini penulis akan merancang struktur dengan menggunakan data laporan polisi untuk pembuatan aplikasi yang akan dibangun, dengan menggunakan alur sistem secara keseluruhan dari sistem yang akan dibuat agar dapat mengidentifikasi dan mengatasi permasalahan-permasalahan yang terjadi.

\subsection{Profil Polsek Kedawung}

Kepolisian Sektor kota cirebon (Polsek Kedawung kota cirebon) merupakan suatu instansi pemerintahan yang bergerak dibidang kepolisian, Polsek kedawung yang berada di jajaran Kepolisian Resor Kota Cirebon (Polresta Kota Cirebon). Wilayah hukum polsek kedawung mencangkup 2 (dua)kecamatan, yaitu kecamatan kedawung dan kecamatan tengah tani. Polsek Kedawung terletak di jalan Ir. H. Juanda Nomor 23 Kecamatan Kedawung Kota Cirebon. Merupakan satuan kerja kewilayahan yang dipimpin oleh seorang Kapolsek dan dibantu oleh seorang wakapolsek.

Polsek kedawung dapat melayani masyarakat yang ingin membuat laporan dan pengaduan terkait tindak pidana, pencurian, pemukulan, hingga permohonan perlindungan. Pengaduan dan pelaporan dari masyarakat akan diterima dan diproses lebih lanjut oleh pihak kepolisian sesuai dengan hukum yang berlaku. Polsek kedawung juga melayani masyarakat yang ingin cek perkembangan proses pelaporan atau laporan polisi. 


\subsection{Struktur Organisasi}

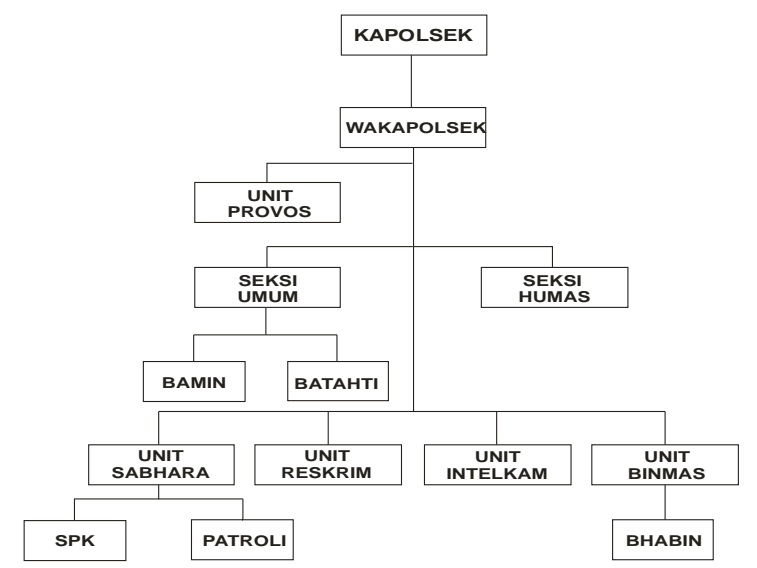

Gambar 1. Struktur Organisasi Polsek Kedawung

\section{ANALISIS DAN PERANCANGAN}

\subsection{Analisis Sistem Berjalan}

Flowmap manual ini terdiri dari entitas yang terlibat dalam pendataan data laporan polisi yaitu : Masyarakat/Polisi, Sentra Pelayanan Kepolisian (SPK), Kapolsek. Dengan flowmap yang ada penulis bertujuan agar dapat menjadi gambaran secara manual pendatana laporan polisi pada Polsek Kedawung.

Laporan Polisi Model A adalah peristiwa pidana yang ditemukan sendiri oleh petugas polisi tentang terjadinya suatu peristiwa pidana dimana peristiwa itu tidak memiliki korban. Keterangan Flowmap Manual Data Laporan Polisi Model A :

1. Polisi Menemukan peristiwa pidana yang terjadi.

2. Polisi akan membuat Surat Tanda Bukti Laporan.

3. Polisi akan mencatat laporan polisi di buku besar dan membuatkan laporan polisi yang berisi 8 rangkap yang akan di tandatangani oleh kapolsek

4. Laporan Polisi yang sudah di tandatangani oleh kapolsek berisi 8 rangkap yaitu 1 rangkap untuk arsip, 4 rangkap untuk pemberkasan perkara, 2 untuk kejaksaan dan 1 untuk pengadilan.

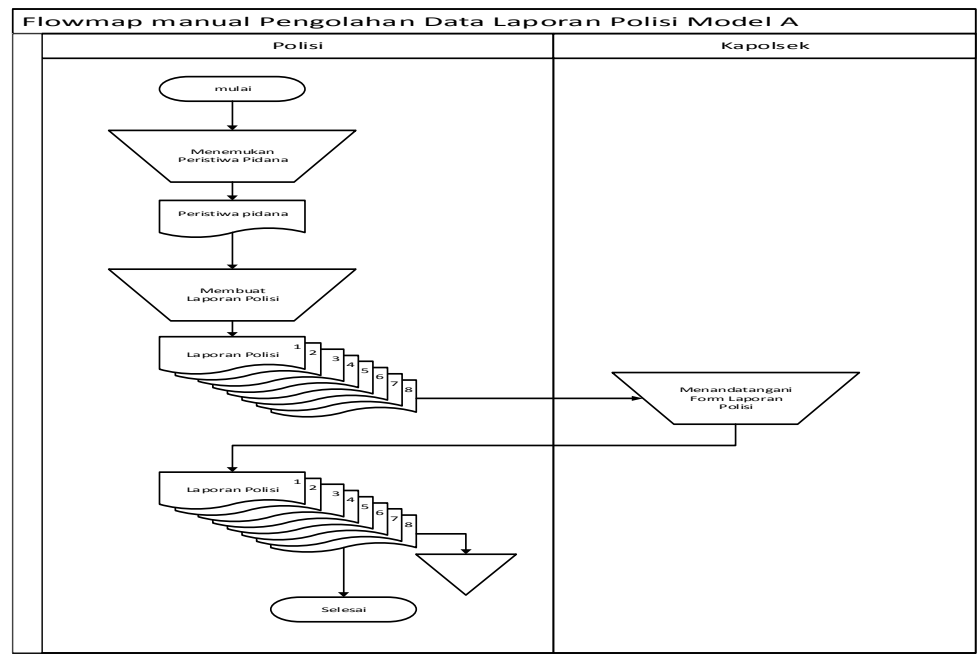

Gambar 2. Analisis Sistem Berjalan Bagian 1

Flowmap manual ini terdiri dari entitas yang terlibat dalam pendataan data laporan polisi yaitu:Masyarakat, Sentra Pelayanan Polisi, Kapolsek. Dengan flowmap yang ada penulis bertujuan agar dapat menjadi gambaran secara manual alir pendataan laporan polisi pada Polsek Kedawung.

Laporan Polisi Model B adalah peristiwa pidana yang ditemukan oleh masyarakat tentang terjadinya suatu peristiwa pidana dimana tersangkanya belum diketahui.Keterangan Flowmap Manual Data Laporan Polisi Model B : 
1. Masyarakat akan melaporkan peristiwa pidanan kepada kepolisian

2. Sentra Pelayanan Kepolisian akan membuat Surat Tanda Bukti Laporan.

3. Sentra Pelayanan Kepolisian akan mencatat peristiwa pidanan di buku besar dan membuatkan Laporan Polisi 8 rangkap yaitu 1 untuk arsip, 4 untuk pemberkasan perkara, 2 untuk kejaksaan, dan 1 untuk pengadilan yang akan ditanda tangan oleh kapolsek.

4. Kapolsek akan menandatangai laporan polisi dan akan menyerahkan kembali pada bagian Sentra Pelayanan Kepolisian

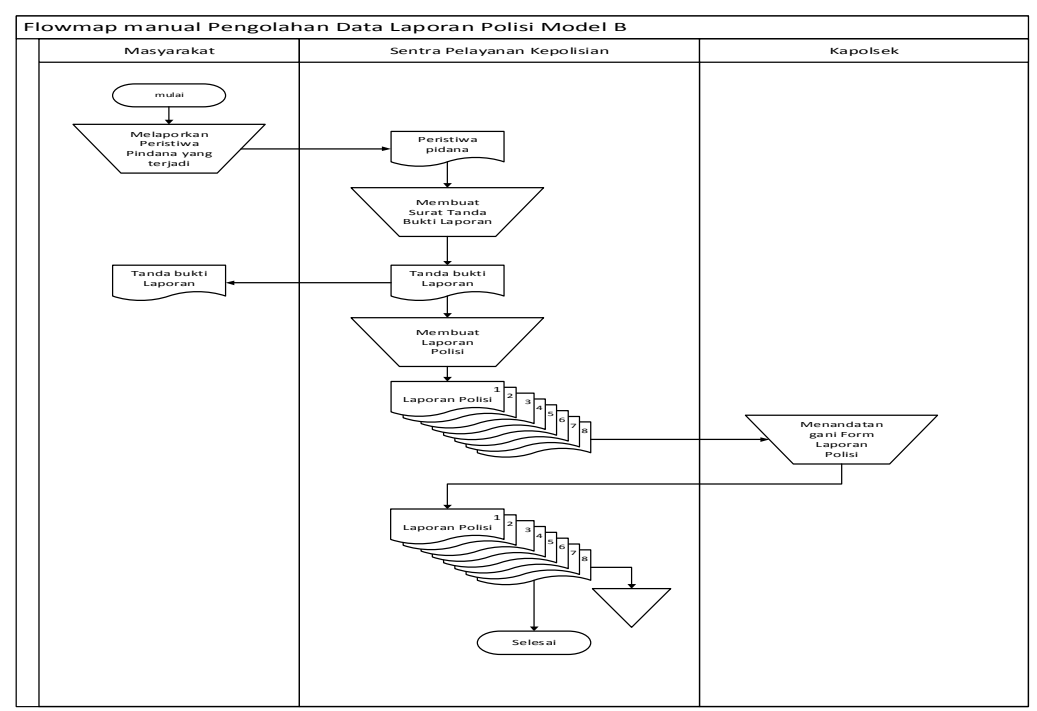

Gambar 3.Analisis Sistem Berjalan Bagian 2

Flowmap manual ini terdiri dari entitas yang terlibat dalam pendataan data laporan polisi yaitu : Masyarakat dan Sentra Pelayanan Kepolisian. Dengan flowmap yang ada penulis bertujuan agar dapat menjadi gambaran secara manual alir pendataan laporan polisi pada Polsek Kedawung.

Laporan Polisi Model C adalah bentuk laporan polisi untuk kehilangan/kerusakan barang, surat keterangan kehilangan.

Keterangan Flowmap Manual Data Laporan Polisi Model C :

1. Masyarakat melaporkan peristiwa kehilangan barang, seperti Kartu Tanda Penduduk (KTP), Kartu Keluarga (KK), Ijasah dan lain sebegainya, membawa kartu keluarga, kartu tanda penduduk.

2. Sentra Pelayanan Kepolisian akan mencatat laporan kehilangan dibuku besar dan membuat surat tanda penerimaan laporan untuk masyarakat.

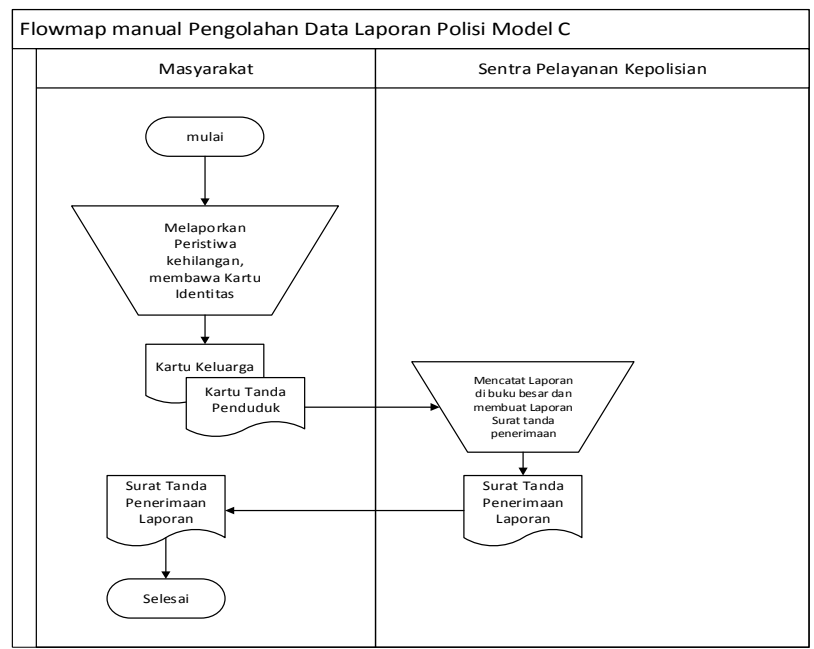

Gambar 4. Analisis Sistem Berjalan Bagian 3 


\subsection{Analisis Sistem Komputerisasi}

Uraian hasil analisa flowmap manual memiliki kekurangan antara lain: proses pendataan laporan polisi model A, B, C dan Data Surat Berkas Perkara yang hanya dicatat dalam buku, oleh karena itu penulis membuat sistem usulan agar aplikasi ini dapat mempermudah proses pengolahan data laporan polisi dan data Surat berkas perkara pada polsek kedawung.

\subsubsection{Bagian yang terkait}

Bagian-bagian yang terkait dalam aplikasi pendataan laporan polisi dan pada polsekkedawung adalah sebagai berikut :

1. Sentra Pelayanan Kepolisian (SPK) dapat mengelola data dan mencetak laporan laporan polisi.

2. Reserse Kriminal (RESKRIM) dapat mengelola data dan mencetak data berkas perkara.

3. Kapolsek dapat melihat data laporan polisi dan data berkas perkara.

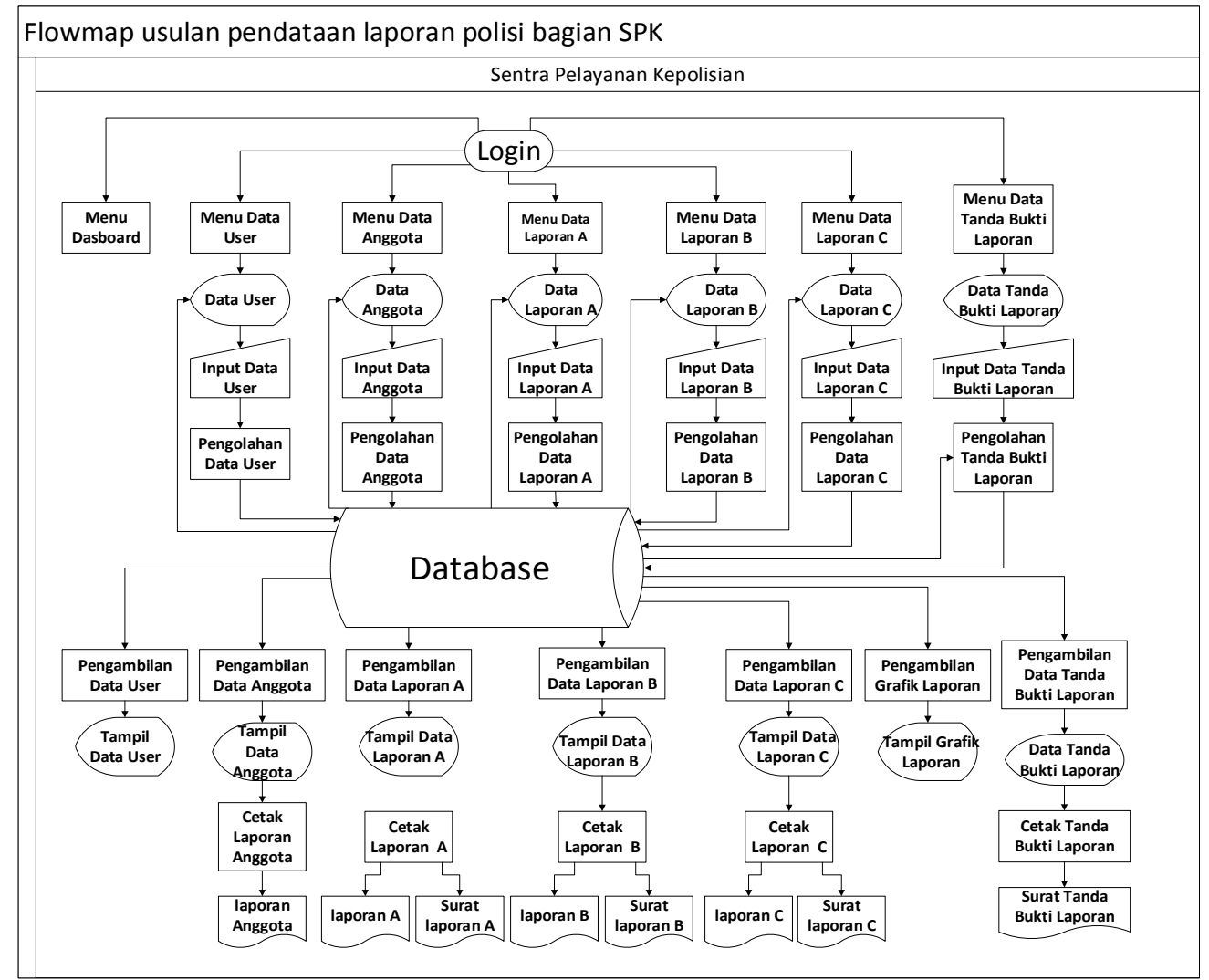

Gambar 5.Analisis Sistem Komputerisasi Bagian 1

Naratif flowmap usulan sebagai berikut :

Sentra Pelayanan Kepolisian (SPK) memiliki menu data laporan polisi model A, B, dan C kemudaian sentra pelayanan kepolisiann menginput data user, data anggota dan data laporan polisi model A, B, C dan data tanda bukti lapran lalu mengolah data dan disimpan ke dalam database. Bagian sentra pelayanan kepolisian dapat melihat data laporan polisi, data laporan polisi model A, B dan C. Setelah itu data yang sudah diolah dapat dicetak sebagai laporan anggota, surat laporan polisi model A, surat laporan polisi model B, surat laporan polisi model C, Laporan Polisi model A, B, C dan surat tanda bukti laporan. 


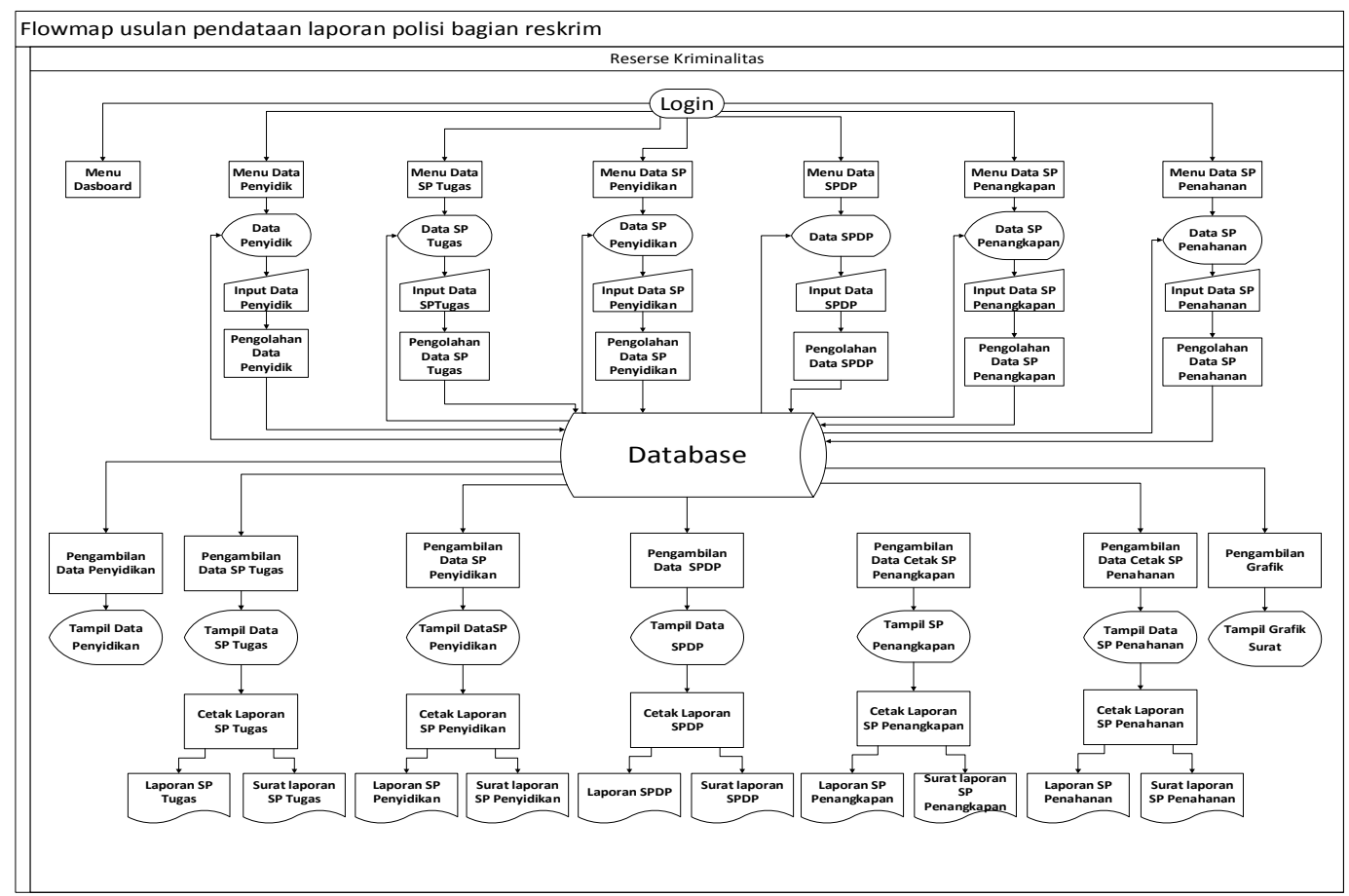

Gambar 6. Analisis Sistem Komputerisasi Bagian 2

Naratif flowmap usulan sebagai berikut :

Reserse Kriminal (RESKRIM) memiliki menu data surat perintah tugas, surat perintah penyidikan, surat pemberitahuan dimulainya penyidikan, surat perintah penangkapan, surat perintah penahananlalu mengolah data dan disimpan kedalam database. Bagian reserse kriminal dapat melihat data menu data surat perintah tugas, surat perintah penyidikan, surat pemberitahuan dimulainya penyidikan, surat perintah penangkapan dan surat perintah penahanan. Setelah itu data yang sudah diolah dapat dicetak sebagai suratulir.

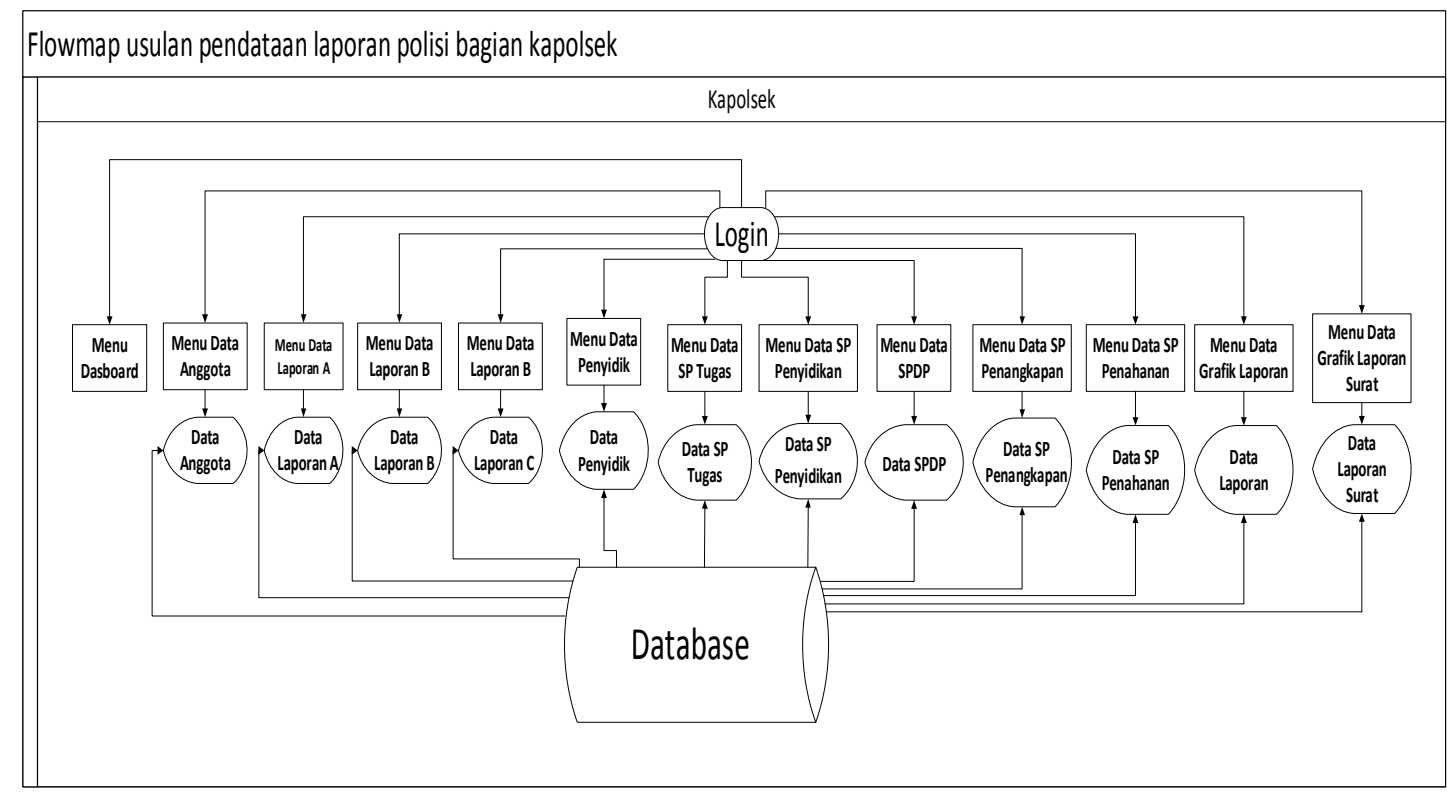

GaGambar 7. Analisis Sistem Komputerisasi Bagian 3

Naratif flowmap usulan sebagai berikut :

Kapolsek dapat melihat data laporan polisi model A,B, C, data anggota, data penyidik dan laporan surat berkas perkara. 
JURNAL DIGIT Vol. 9, No.2 Nov 2019, pp.225 236

\subsection{Diagram Konteks}

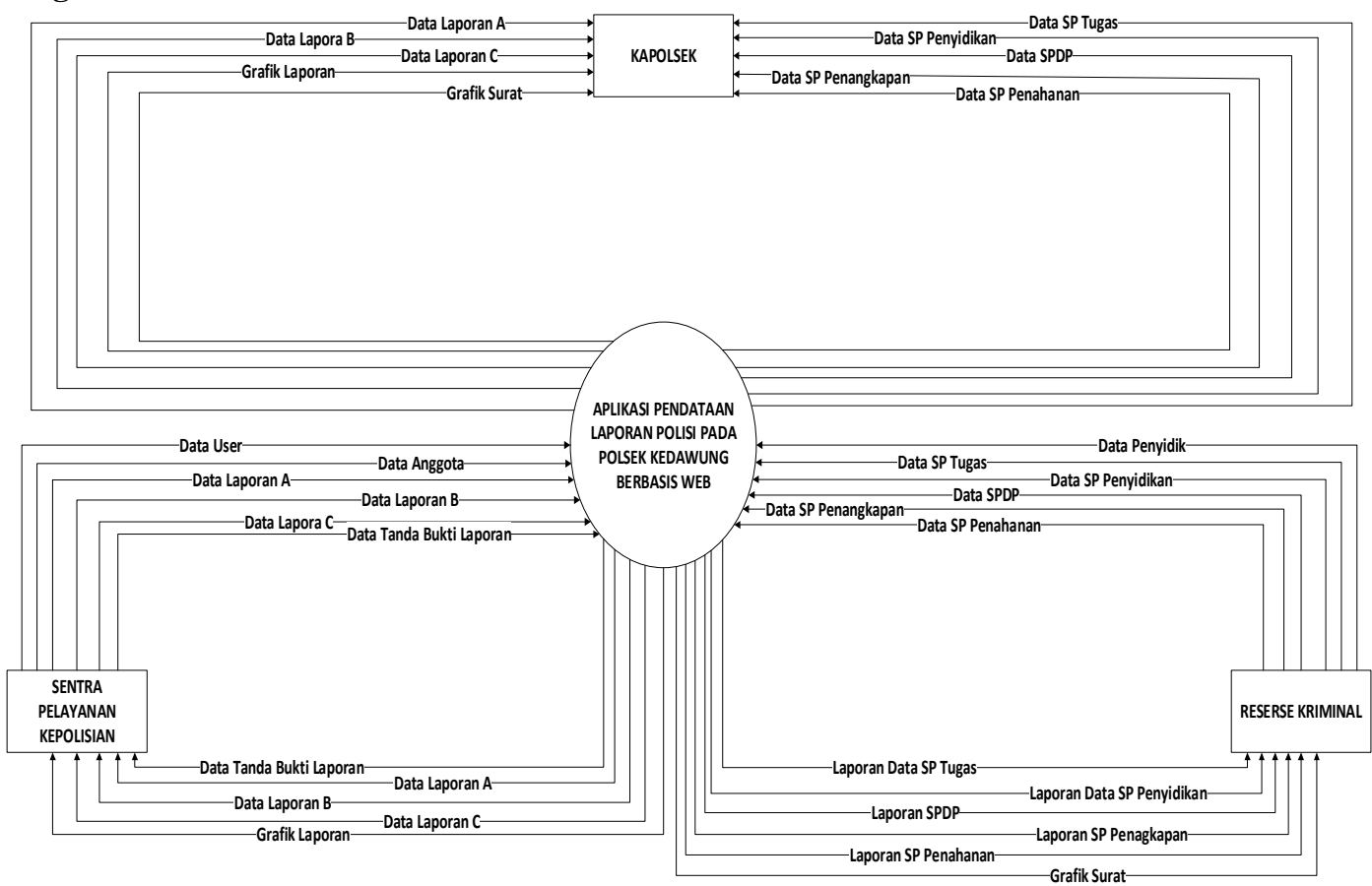

Gambar 8. Diagram Konteks

\subsection{Diagram Alir Data Level 0}

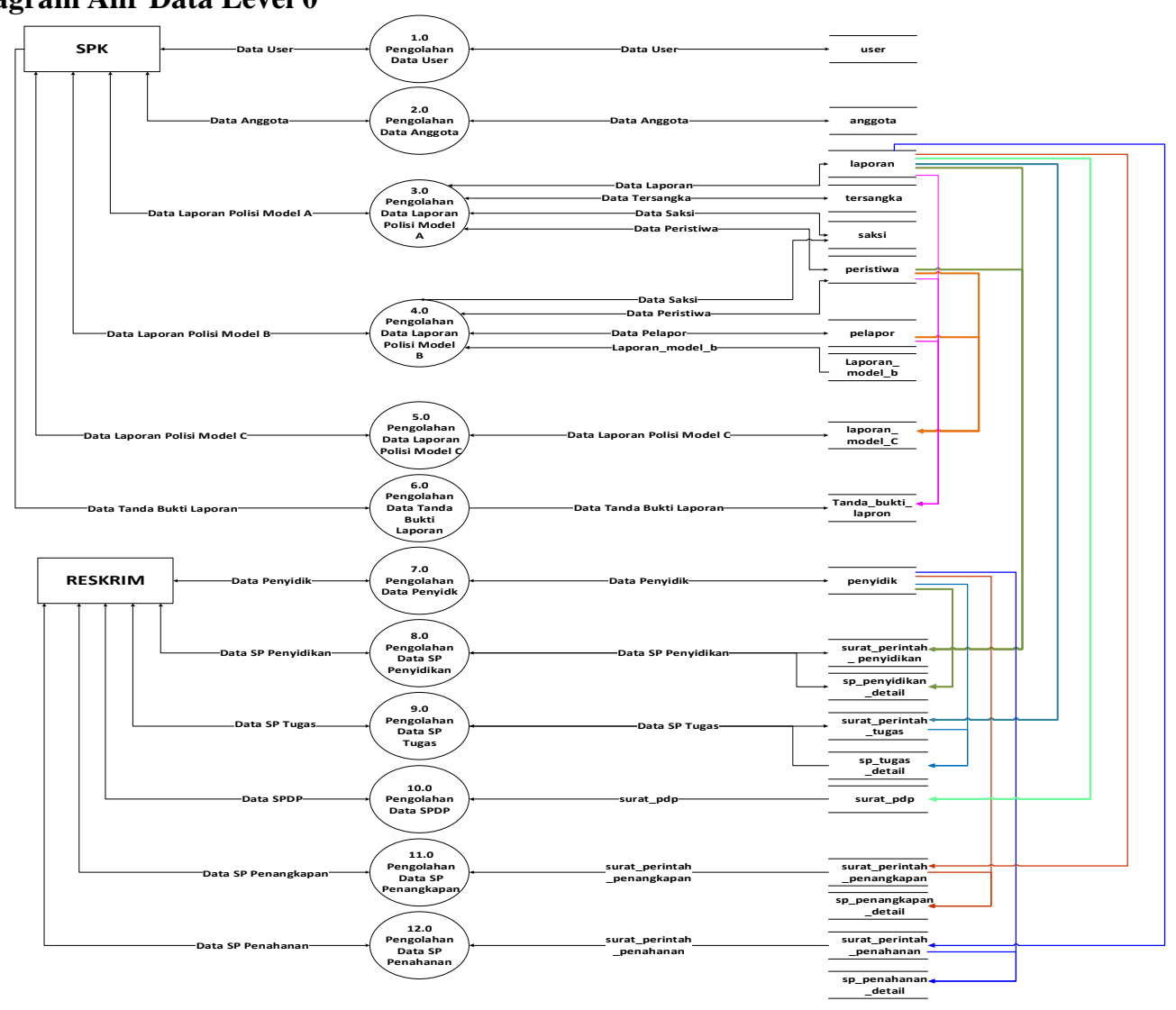

Gambar 9. Diagram Alir Data Level 0 Bagian 1 


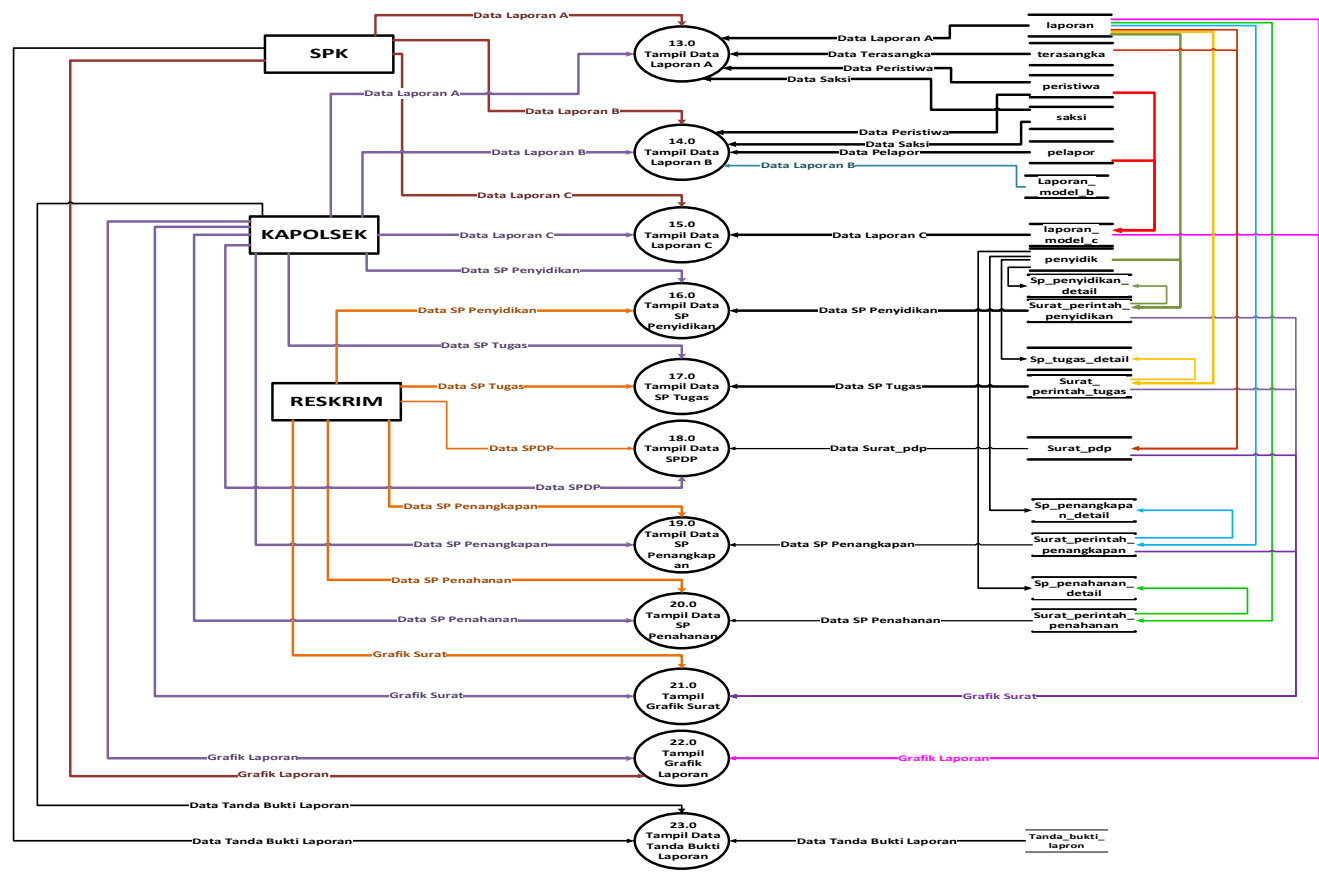

Gambar 10. Diagram Alir Data Level 0 Bagian 2

\subsection{Entity Relationship Diagram (ERD)}

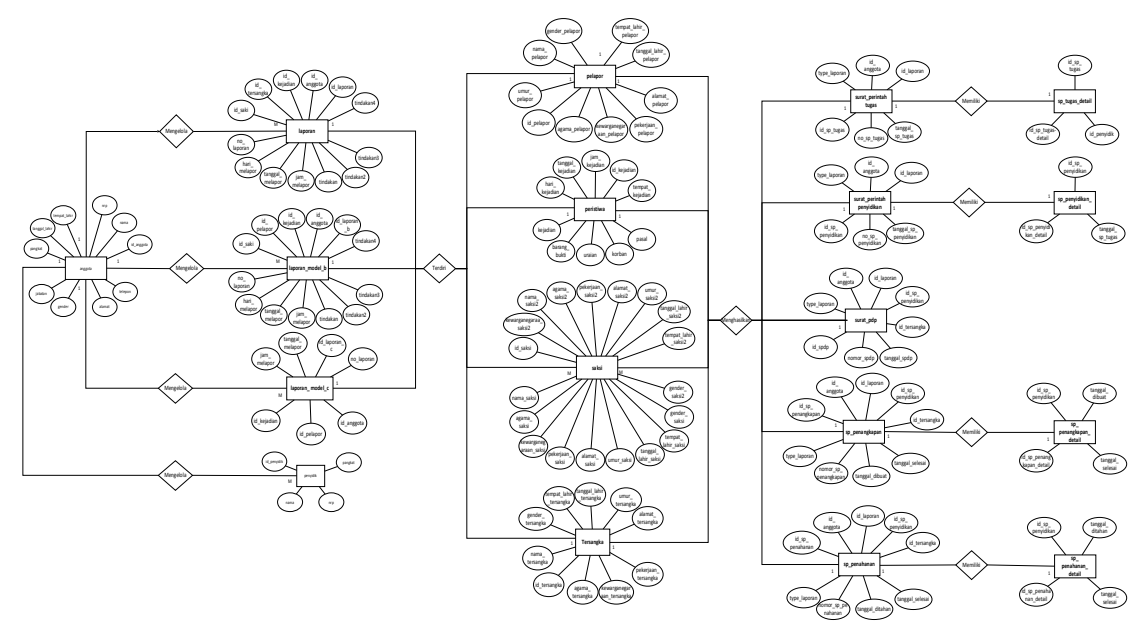

Gambar 11.Entity Relationship Diagram (ERD)

\subsection{Rancangan Data Tabel}

1. Tabel User

Table ini digunakan untuk menyimpan data user, menambah user dan mengubah password user

Nama Tabel

Primary Key

: User

Fungsi

: id_user

: Untuk menyimpan data-data $u$ ser.

Tabel 1.Tabel User

\begin{tabular}{|l|l|l|l|l|}
\hline No & Nama Field & Tipe Data & Ukuran Field & Keterangan \\
\hline 1 & id_user & Int & 11 & Primary Key \\
\hline 2 & Nama_user & Varchar & 50 & Nama Lengkap \\
\hline 3 & nrp & Int & 10 & Nomor Registrasi Pokok \\
\hline 4 & gambar & Text & & Foto user \\
\hline
\end{tabular}


JURNAL DIGIT Vol. 9, No.2 Nov 2019, pp.225 236

ISSN 2088-589X

\begin{tabular}{|l|l|l|l|l|}
\hline 5 & username & Varchar & 50 & Nama User \\
\hline 6 & password & Varchar & 100 & Kata Sandi \\
\hline 7 & jabatan & Enum & ('spk','reskim','kapolsek') & Peran User \\
\hline 8 & Pangkat_user & Varchar & 50 & Pangkat User \\
\hline
\end{tabular}

2. Tabel Laporan Model A

Table ini digunakan untuk menyimpan data laporan, menambah data laporan dan dapat mengubah data laporan

Nama Tabel

Primary Key

: laporan

Fungsi

: id_laporan

: Untuk menyimpan data-data laporan.

Tabel 2Tabel LaporanModel A

\begin{tabular}{|l|l|l|l|l|}
\hline No & Nama Field & $\begin{array}{l}\text { Tipe } \\
\text { Data }\end{array}$ & Ukuran Field & Keterangan \\
\hline 1 & id_laporan & Int & 11 & Primary Key \\
\hline 2 & id_kejadian & Int & 11 & Foreign Key \\
\hline 3 & id_tersangka & Int & 11 & Foreign Key \\
\hline 4 & id_saksi & Int & 11 & Foreign Key \\
\hline 5 & id_anggota & Int & 11 & Foreign Key \\
\hline 6 & no_laporan & Varchar & 80 & No Laporan Polisi Model A \\
\hline 7 & tindakan2 & Varchar & 80 & Tindakan yang Dilakukan Polisi \\
\hline 8 & tindakan3 & Varchar & 'laporan_a','laporan_b' & Tindakan yang Dilakukan Polisi \\
\hline 9 & hari_melapor & Enum & $\begin{array}{l}\text { 'senin','selasa','rabu','kamis', ' } \\
\text { jumat','sabtu', 'minggu' }\end{array}$ & Hari Melapor \\
\hline 10 & tanggal_melapor & Date & & Tanggal Melapor \\
\hline 11 & Jam_melapor & Time & & Jam Melapor \\
\hline 12 & tindakan & Varchar & 80 & Tindakan yang Dilakukan Polisi \\
\hline
\end{tabular}

3. Tabel Laporan Model B

Table ini digunakan untuk menyimpan data laporan, menambah data laporan dan dapat mengubah data laporan

Nama Tabel

Primary Key

Fungsi

: laporan_model_b

: id_laporan_b

: Untuk menyimpan data-data laporan.

Tabel 3.Tabel Laporan Model B

\begin{tabular}{|c|c|c|c|c|}
\hline No & Nama Field & Tipe Data & Ukuran Field & Keterangan \\
\hline 1 & id_laporan_b & Int & 11 & Primary Key \\
\hline 2 & id_kejadian & Int & 11 & Foreign Key \\
\hline 3 & id_pelapor & Int & 11 & Foreign Key \\
\hline 4 & id_saksi & Int & 11 & Foreign Key \\
\hline 5 & id_anggota & Int & 11 & Foreign Key \\
\hline 6 & no_laporan & Varchar & 80 & No Laporan Polisi Model A \\
\hline 7 & tindakan2 & Varchar & 80 & Tindakan yang Dilakukan Polisi \\
\hline 8 & tindakan3 & Varchar & 'laporan_a','laporan_b' & Tindakan yang Dilakukan Polisi \\
\hline 9 & hari_melapor & Enum & $\begin{array}{l}\text { 'senin', 'selasa', 'rabu', 'kamis } \\
\text { ', 'jumat', 'sabtu', 'minggu' }\end{array}$ & Hari Melapor \\
\hline 10 & tanggal_melapor & Date & & Tanggal Melapor \\
\hline
\end{tabular}




\begin{tabular}{|l|l|l|l|l|}
\hline 11 & Jam_melapor & Time & & Jam Melapor \\
\hline 12 & tindakan & Varchar & 80 & Tindakan yang Dilakukan Polisi \\
\hline
\end{tabular}

4. Tabel Laporan Polisi Model C

Tabel ini digunakan untuk menyimpan data laporan polisi model $\mathrm{C}$, menambah data laporan polisi model $\mathrm{C}$ dan dapat mengubah data laporan polisi model $\mathrm{C}$

Nama Tabel : : laporan_model_c

Primary Key : :id_laporan_c

Fungsi : Untuk menyimpan data-data laporan polisi model c.

Tabel 4.Tabel Laporan Polisi Model C

\begin{tabular}{|l|l|l|l|l|}
\hline No & Nama Field & Tipe Data & Ukuran Field & Keterangan \\
\hline 1 & id_laporan_c & Int & 11 & Primary Key \\
\hline 2 & id_kejadian & Int & 11 & Foreign Key \\
\hline 3 & id_pelapor & Int & 11 & Foreign Key \\
\hline 4 & no_laporan & Varchar & 50 & No Laporan Polisi Model B \\
\hline 5 & hari_melapor & Varchar & 7 & Hari Melapor \\
\hline 6 & tanggal_melapor & Date & & Tanggal Melapor \\
\hline 7 & jam_melapor & Time & & Jam Melapor \\
\hline
\end{tabular}

\subsection{Tampilan Halaman Web}

\subsubsection{Halaman Login}

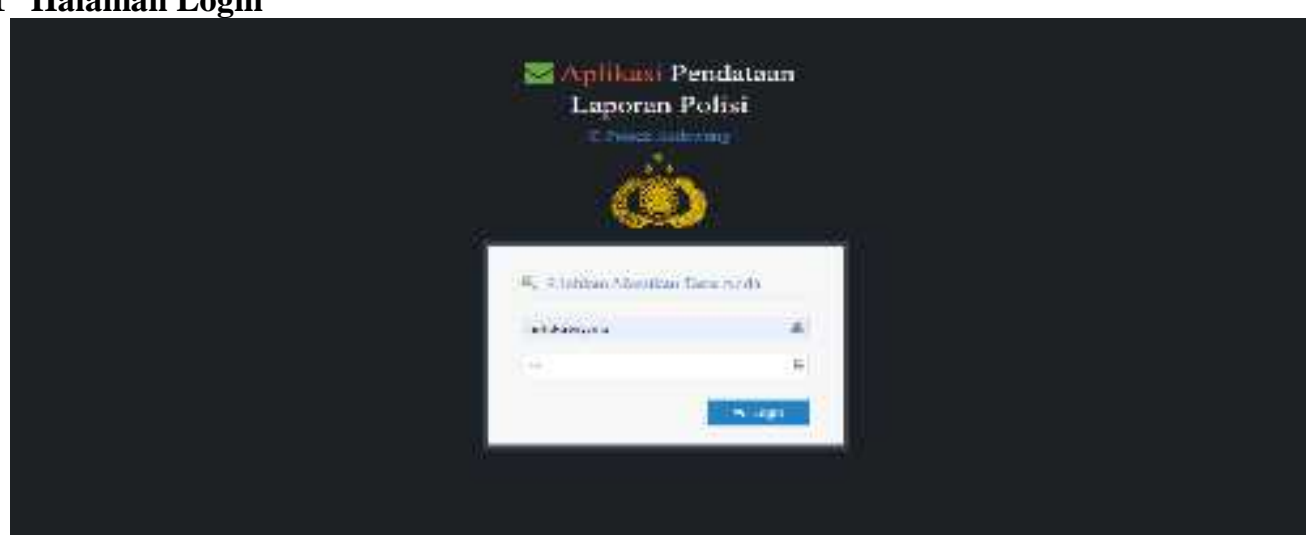

Gambar 11.Halaman Login

\subsubsection{Halaman Laporan Polisi Model A}

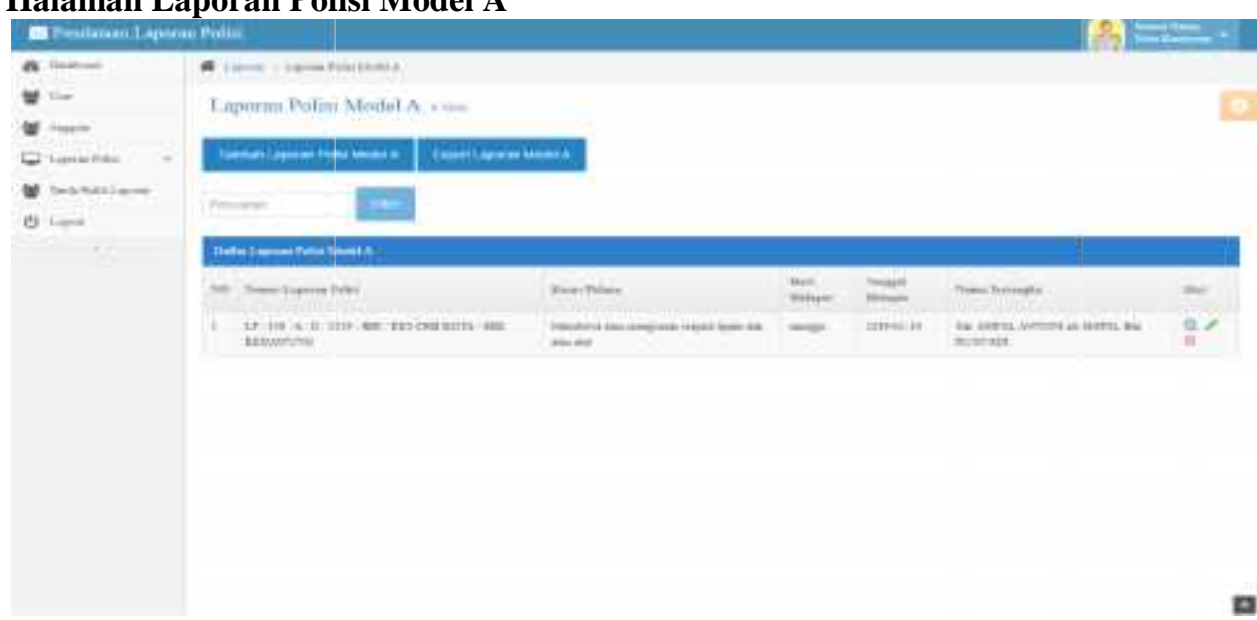

Gambar 12.Halaman Laporan Polisi Model A

3.7.3 Halaman Laporan Polisi Model B 


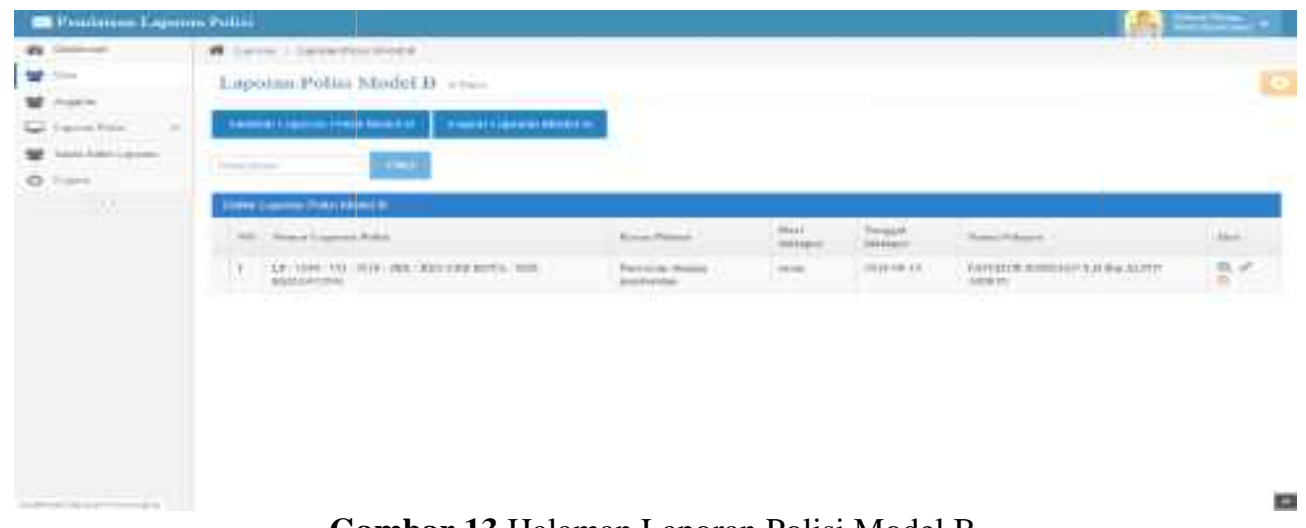

Gambar 13.Halaman Laporan Polisi Model B

\subsubsection{Halaman Laporan Polisi Model C}

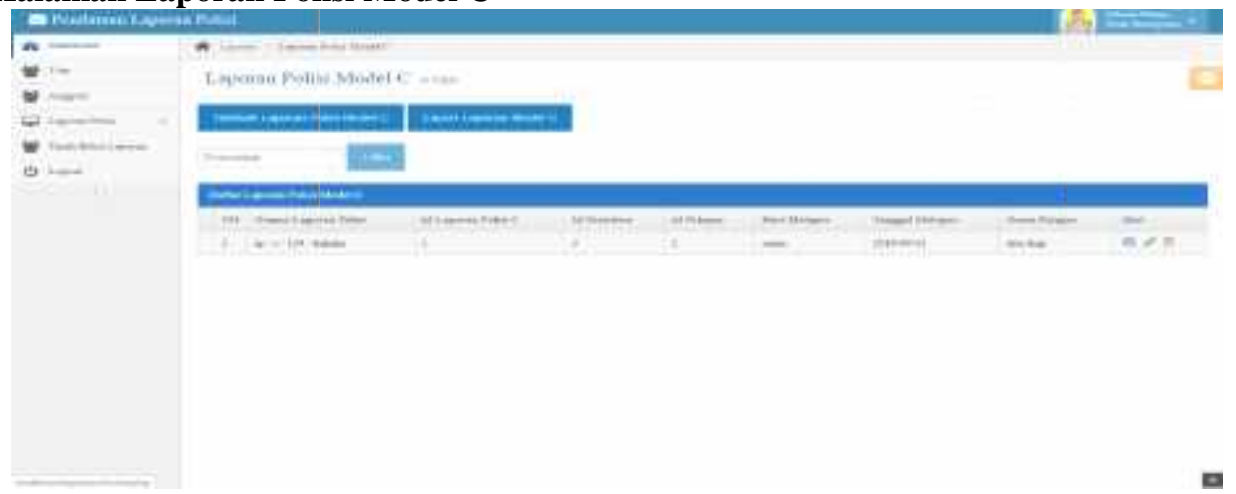

Gambar 14.Halaman Laporan Polisi Model C

\section{KESIMPULAN}

Setelah Melalui tahap analisa, perancangan, dan implementasi, maka penulis menarik kesimpulan sebagai berikut :

1. Aplikasi ini menjawab kebutuhan suatu instansi kepolisian pada polsek kedawunng berupa aplikasi pendataan laporan polisi. Memudahkan proses pencarian data laporan polisi dan surat berkas perkara yang dapat dilakukan dengan cepat.

2. Aplikasi ini memudahkan proses penyimpanan dan pengolahan data laporan polisi model A, laporan polisi model $\mathrm{B}$, laporan polisi model $\mathrm{C}$, surat perintah tugas, surat perintah penyidikan, surat perintah dimulainya penyidikan, surat penangkapan, dan surat penahanan.

3. Aplikasi ini menyediakan informasi mengenai grafik laporan polisi model A, laporan polisi model $\mathrm{B}$, laporan polisi model C, surat perintah tugas, surat perintah penyidikan, surat perintah dimulainya penyidikan, surat penangkapan, dan surat penahanan.

\section{REFERENSI}

[1] A.S, Rosa dan Shalahuddin, M, 2018 "Rekayasa Perangkat Lunak Tersruktur dan Berorientasi Objek". Bandung. Informatika

[2] Hendratman, Hendi, 2018 "The Magic Of CorelDraw". Bandung. Informatika

[3] Hidayatullah, Priyanto dan Khairul Kawista, Jauhari, 2017 "Pemograman Web". Bandung. Informatika.

[4] Krismiaji, 2010. Sistem Informasi Akuntansi. Edisi Ketiga. Yogyakarta: Unit Penerbit Dan Percetakan Sekolah Tinggi Ilmu Manajemen YKPN.

[5] Napitulu, Darmawan dan Sutabri, Tata, 2019 "Sistem Informasi Bisnis" Andi Published.

[6] Raharjo, Budi, 2016 "Modul Pemrograman WEB (HTML, PHP \& MySQL)", 2016. Bandung. Modula. 
[7] Rahman, Su, 2018 “Menjadi Web Entrepreneur, Siapa Takut!”. Jakarta. PT Elex Media Komputindo.

[8] Rochaety, Eti. 2016. Sistem Informasi Manajemen. Jakarta. Miitra Wacana Media.

[9] Sutabri, Tata, 2012. Konsep Sistem Informasi. Yogyakarta: CV. Andi Offset.

[10] Susanto, Azhar. 2009. Sistem Informasi Manajemen. Lingga Jaya. Bandung.

[11] Undang-Undang Nomor 2 Tahun 2002 tentang Kepolisian Republik Indonesia.

[12] Undang-Undang Nomor 25 Tahun 2009 tentang Pelayan Publik.

[13] Undang-Undang Nomor 12 Tahun 2009 tentang Laporan Polisi. 